\title{
Introduction to the special issue on ICECS 2008
}

\author{
Joseph Micallef · Ivan Grech
}

Published online: 28 May 2011

(C) Springer Science+Business Media, LLC 2011

This Special Issue of the Journal of Analog Integrated Circuits and Signal Processing consists of the expanded version of selected papers originally presented at the 15 th IEEE International Conference on Electronics, Circuits and Systems, ICECS 2008, held in Malta in September 2008.

The papers presented here were selected after a thorough process of peer-review which involved the assessment by at least two expert reviewers per paper. Compiling this Special Issue has been a challenging task and we are aware that we probably missed other excellent contributions.

The papers collected in this Special Issue cover a wide variety of topics in Analog Integrated Circuits and Signal Processing fields including wireless communications, medical applications, data conversion, RF MEMS, voltage references and analog baseband processing. Novel techniques and circuit solutions are proposed and in most cases validated through chip fabrication and experimental results.

The guest editors are grateful to Professor Mohamed Ismail for the opportunity to present this Special Issue, and wish to thank Professor Franco Maloberti for his contribution during the paper selection process, all of the reviewers and contributing authors for their assistance, as well the Springer personnel for the competent and efficient support provided while compiling this Special Issue.

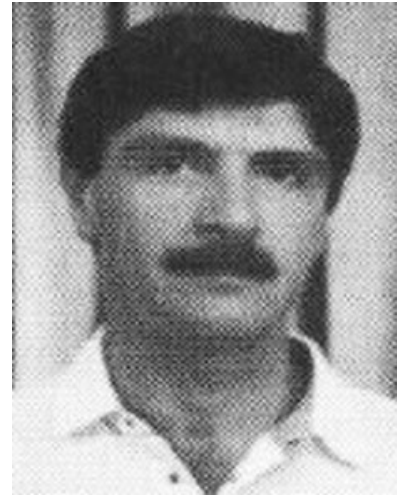

Joseph Micallef received his B.Sc. Eng. (Hons.) degree in electronics engineering from the University of Malta in 1972, and M.Sc. and Ph.D. degrees in electrical engineering from the University of Surrey, UK in 1989 and 1993, respectively. From 1973 to 1981 , he was with General Instruments, engaged in work on high voltage components and circuits and on IFTs. He moved to SGS-THOMSON Microelectronics in 1981 where he was involved with packaging of MOS ICs. In 1989, he joined the University of Malta and is now professor in the Department of Microelectronics and Nanoelectronics. His current research activities include analog integrated circuit design, as well as optical properties of III-V quantum well structures.

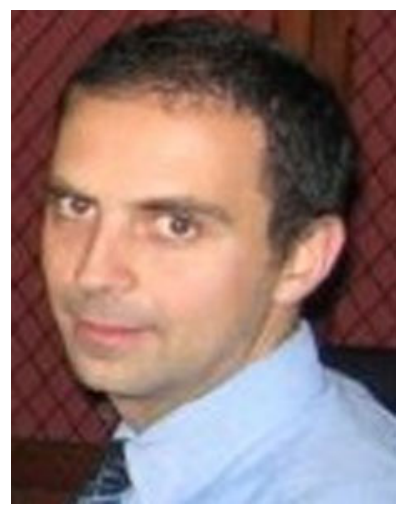

Ivan Grech received his B.Eng. (Hons.) degree in 1993 and M.Sc. in 1996 from the University of Malta. In 1994 he joined the University of Malta and is now senior lecturer in the Department of Microelectronics and Nanoelectronics. He received the Ph.D. degree from the University of Surrey, UK in 2002. His research interests focus on CMOS analog integrated circuit design, embedded systems and MEMS design.

\footnotetext{
J. Micallef $(\bowtie) \cdot$ I. Grech $(\bowtie)$

Department of Microelectronics and Nanoelectronics,

University of Malta, Msida, Malta

e-mail: joseph.micallef@um.edu.mt

I. Grech

e-mail: ivan.grech@um.edu.mt
} 